\title{
SOSIALISASI PEMANFAATAN SAMPAH ORGANIK MENJADI PUPUK CAIR ORGANIK DI DESA BINAAN UMN
}

\author{
Indiwan Seto Wahjuwibowo ${ }^{1}$ \\ ${ }^{1}$ Universitas Multimedia Nusantara Tangerang Banten \\ indiwan@umn.ac.id
}

\begin{abstract}
Abstrak
Salah satu faktor pendukung aspek Smart Village adalah pengelolaan limbah masyarakat baik berupa sampah organik maupun anorganik. Pengelolaan sampah organik maupun anorganik merupakan suatu faktor pendukung utama. Apabila sampah ini tidak dikelola dengan baik, dapat mengakibatkan beberapa akibat yaitu: 1) Sampah bisa menyebabkan pencemaran udara karena terdapat gas-gas yang menimbulkan bau yang tidak sedap; 2) Penumpukan sampah mengakibatkan kondisi ketidaknyamanan kehidupan lingkungan sekitarnya; 3) minim oksigen terjadi karena selama proses perombakan sampah menjadi senyawa- senyawa yang diperlukan oksigen yang telah diambil dari udara sekitar tempat pembuangan sampah; 4) gas yang dihasilkan selama proses pembusukan sampah bisa membahayakan kesehatan karena bisa jadi sampah tersebut mengandung gas beracun; 5) menyebabkan terjadinya penularan penyakit melalui hewan, misalnya lalat atau serangga lain; 6) Tempat pembuangan sampah menjadi tempat yang kurang indah dipandang dan lingkungan tersebut tidak nyaman untuk ditempati. Itulah yang membuat sejumlah dosen di Universitas Multimedia Nusantara melakukan sosialisasi dan praktik mengubah sampah organik menjadi pupuk cair organik dengan teknik yang sederhana memanfaatkan barang-barang bekas yang ada di desa. pemanfaatan pupuk organik untuk tanah sangat membantu memperbaiki struktur tanah, meningkatkan permeabilitas tanah, dan mengurangi ketergantungan lahan pada pupuk anorganik. Selain itu, pupuk organik juga berperan sebagai sumber makanan bagi mikroorganisme tanah. Efek positifnya, dapat meningkatkan jumlah dan aktivitas mikroorganisme tanah sehingga tanah menjadi gembur dan mudah menyerap air
\end{abstract}

Kata Kunci: pupuk cair organik, desa binaan, pengelolaan sampah organik, sosialisasi

\section{PENDAHULUAN}

Jumlah sampah warga Kota Tangerang yang diangkut petugas Dinas Lingkungan Hidup saat periode lebaran 2020 mencapai 1.543 ton.
"Volume sampah pada hasil pengangkutan pada malam takbir yaitu sebanyak 1400 ton dan hari rayanya 143 ton. Jadi, total 1.543 ton," ujar Dedi Suhada, Kepala Dinas Lingkungan Hidup Kota Tangerang kepada Tangerang News, Selasa 
(26/5/2020). Sampah-sampah tersebut sangat menggangu kenyamanan dan kebersihan warga Tangerang dan sekitarnya.

Di lokasi lain Volume sampah di Kota Tangsel meningkat sejak diberlakukannya pembatasan sosial berskala besar (PSBB). Peningkatan mencapai 10 persen.

Hal tersebut dikatakan Kepala Dinas Lingkungan Hidup Kota Tangsel Toto Sudarto di Puspemkot Tangsel, Jalan Maruga Raya, Ciputat, Tangsel, Senin (4/5/2020). "Peningkatan sampah memang ada (terjadi) 10 persen," kata Toto. Peningkatan tersebut rata-rata terjadi hanya pada sampah yang berasal dari rumah warga (sampah rumah tangga). "Kalau dari restauran dan perhotelan berkurang karena tutup selama PSBB. Sedangkan untuk di pasar itu stabil," imbuhnya.

Ditambahkan Kepala Seksie (Kasie) Pengelolaan Sampah pada Dinas Lingkungan Hidup Tangsel Rastra Yudhatama, saat ini sampah rumah tangga yang berasal dari rumah warga se-Tangsel mencapai sekitar 80 ton perhari.

"Biasanya (sebelum PSBB) hampir 50 sampai 70 ton sehari, kalau sekarang hampir 80 ton," tutur Yudha. Peningkatan volume sampah itu terjadi lantaran banyak warga yang berdiam di rumah selama pandemi COVID-19 dan berlakunya PSBB. "Jadi dipastikan itu naik 10 persen, karena kebanyakan ibu rumah tangga masak di rumah dan tidak ada kegiatan keluar rumah," katanya.Sementara itu, volume sampah dari sumber lainnya justru menurun, seperti sampah di pinggir jalan.

"Terutama sampah yang ada di pinggir jalan, itu berkurang 30 sampai 40 persen, seperti di bawah fly over Ciputat dan Jalan Kesehatan, Pondok Aren. Karena yang buang itu sumbernya dari pendatang yang mengontrak, dan sekarang sudah pulang kampung sebelum PSBB berlaku," jelas Yudha. Sedangkan, untuk sampah yang berasal dari pasar, masih stabil. Tidak bertambah atau berkurang.

"Yakni sekitar dua bak amrol (dump truk) tiap harinya. Untuk perhotelan dan restauran itu yang berkurang," pungkasnya.

Begitu juga di wilayah Kabupaten Tangerang tempat dimana sejumlah desa binaan Universitas Multimedia Nusantara berada. Saat ini Kabupaten Tangerang sedang mencanangkan Smart City untuk menjadikan Kabupaten Tangerang menjadi kawasan yang dapat mengelola berbagai sumber dayanya secara efektif dan efisien. Pemanfaatan sumber daya tersebut untuk menjawab banyak tantangan terkini dengan memanfaatkan solusi yang inovatif, terintegrasi, dan berkelanjutan. Solusi tersebut bertujuan untuk menyediakan infrastruktur dan memberikan layanan- layanan untuk meningkatkan kualitas hidup warga di daerah tersebut.

Untuk menjalankan tujuan besar tersebut, perlu didukung dari lingkup yang lebih kecil. Menurut data pemerintahan Kabupaten Tangerang terdiri dari 29 Kecamatan, 246 Desa, dan 28 Kelurahan [1]. Dari salah satu desa yang berada di kawasan Kabupaten Tangerang, Lengkong Kulon sedang dalam proses menjadikan desa ini sebagai salah satu desa yang akan menerapkan konsep Smart Village. Untuk melaksanakan konsep tersebut segala aspek yang berada di desa tersebut harus dibenahi terlebih dahulu, agar dapat terlaksana dengan baik.

Salah satu faktor pendukung aspek Smart Village adalah pengelolaan limbah masyarakat baik berupa sampah organik maupun anorganik. Pengelolaan sampah organik maupun anorganik merupakan suatu faktor pendukung utama. Apabila sampah ini tidak dikelola dengan baik, dapat mengakibatkan beberapa akibat yaitu: 1) Sampah bisa menyebabkan pencemaran udara karena terdapat gas-gas yang menimbulkan bau yang tidak sedap; 2) Penumpukan sampah mengakibatkan kondisi ketidaknyamanan kehidupan lingkungan sekitarnya; 3) minim oksigen terjadi karena selama proses perombakan sampah menjadi senyawa- senyawa yang diperlukan oksigen yang telah diambil dari udara sekitar tempat pembuangan sampah; 4) gas yang dihasilkan selama proses pembusukan sampah bisa membahayakan kesehatan karena bisa jadi sampah tersebut mengandung gas beracun; 5) menyebabkan terjadinya penularan penyakit melalui hewan, misalnya lalat atau serangga lain; 6) Tempat pembuangan sampah menjadi tempat yang kurang indah dipandang dan lingkungan tersebut tidak nyaman untuk dihuni

Dimana pada awalnya pengelolaan sampah hanya dibuang kemudian jika diolah dengan teknologi tepat guna menjadi komoditi tertentu. Pengelolaan sampah merupakan suatu hal yang berkaitan dengan pengaturan terhadap penyimpanan

$$
\text { Lingkungan Hidup dan Bencana }
$$


sementara, penimbunan, pemindahan, pengumpulan, pengangkutan, dan pemrosesan sampah[ Sebagai contoh pengelolaan sampah organik menjadi pupuk atau tanah humus. Kemudian pengelolaan sampah anorganik yang pada awalnya berupa botol plastik menjadi potongan bijih plastik yang siap menjadi komoditi bahan baku. Hasil olahan plastik bisa dimanfaatkan sebagai kerajinan tangan yang nantinya bisa meningkatkan perekonomian warga.

Sebagai contoh lain dalam pengelolaan sampah yang terkumpul dapat dilakukan dengan tiga cara yaitu dengan menimbun di tempat tertentu, dengan menggabungkan, dan mendaur ulang atau biasa disebut recycling

Ada beberapa prinsip yang bisa diterapkan pada pengelolaan sampah. Prinsip ini dikenal dengan 4M, $4 \mathrm{M}$ adalah 1) mengurangi (reduce) meminimalisasi barang yang kita pergunakan; 2) menggunakan kembali (reuse) yang mana barang tersebut bisa dipakai kembali atau mengurangi memakai bahan yang hanya bisa digunakan sekali; 3) mendaur ulang (recycle) menggunakan kembali barang-barang yang sudah tidak berguna; 4) mengganti, meneliti barang dan mengganti ke barang yang lebih tahan lama

Di tengah maraknya sampah di kawasan Tangerng, khususnya sampah rumah tangga, kehadiran kegiatan pembuatan pupuk cair organik ini sangat bermanfaat.Pupuk Organik Cair (POCA) adalah larutan hasil dari pembusukan bahan organik yang berasal dari sisa tanaman, kotoran hewan dan manusia yang kandungan unsur haranya lebih dari 1 unsur. Bagi penggemar tanaman, dengan bertanam mereka akan mendapatkan kepuasan batin dan ketentraman.

Itulah yang membuat sejumlah dosen di Universitas Multimedia Nusantara melakukan sosialisasi dan praktik mengubah sampah organik menjadi pupuk cair organik dengan teknik yang sangat sederhana dan murah.

Dimulai dengan beraudensi dengan jurusan Teknik Kimia ITB seputar bagaimana menyiasati pengolahan sampah hingga akhirnya menemukan sebuah teknik pembuatan pupuk cair organik sendiri bekerjasama dengan pimpinan Bumdes Desa
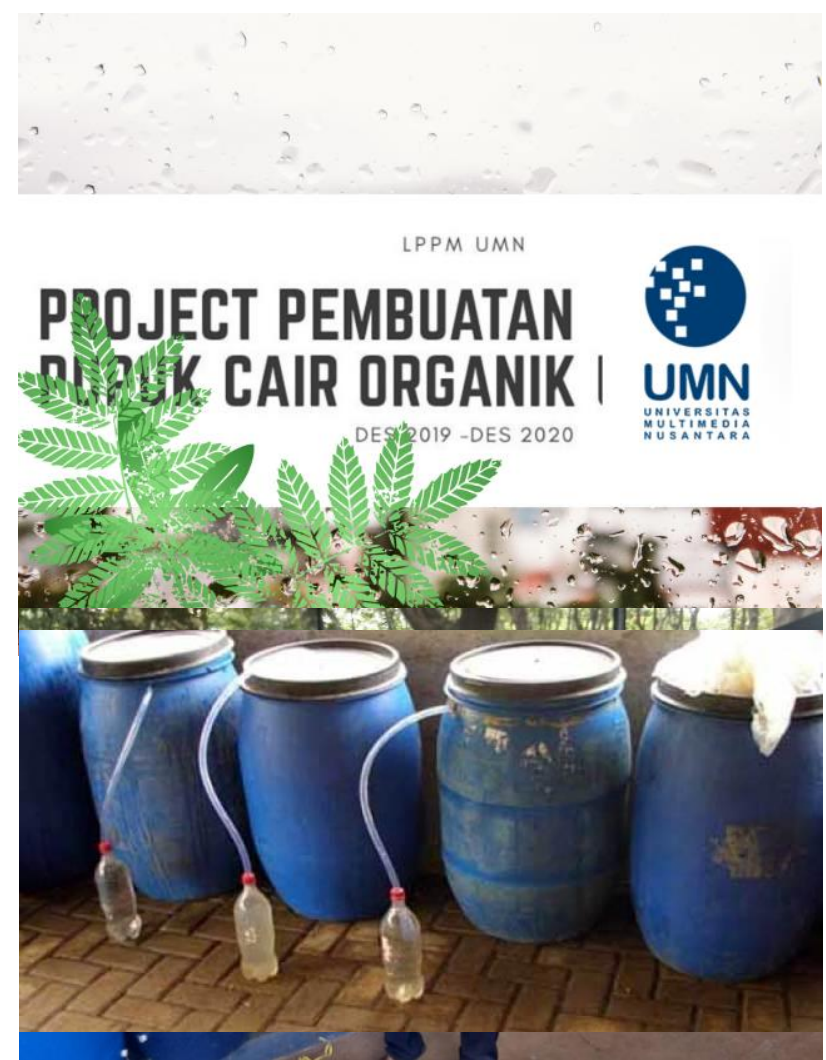

Lengkong Kulon sebagai mitra kerja Universitas Multimedia Nusantara.

Tujuan dan manfaat dari PKM ini adalah untuk membantu desa lengkong kulon dari segi pengelolaan sampah. Pengelolaan ini untuk sampah organik seperti kertas dan plastik atau bisa diolah menjadi kerajinan tangan. Untuk sampah anorganik seperti sisa makanan dan kulit buah. Dari sampah tersebut bisa dijadikan pupuk cair organic. Selain itu hasil dari pengelolaan ini bisa dijual dan menghasilkan uang yang digunakan untuk mengembangkan Desa Lengkong Kulon menjadi lebih baik.

Solusi yang ditawarkan dengan Program Kemitraan Masyarakat ini adalah dengan membuat sistem pengolahan sampah menjadi pupuk cair organik menggunakan peralatan sederhana yang ada di sekitar desa. Para dosen memberikan penyuluhan tentang bagaimana pengelolaan sampah yang baik pada lingkungan Desa Lengkong Kulon. Dan mengubahnya menjadi sesuatu yang bermanfaat bagi masyarakat. 


\section{METODE}

Cara yang dilakukan pertama kali adalah melakukan ujicoba pembuatan pupuk cair organik dengan memmanfaatkan sampah-sampah organik di sekitar kampus UMN, khususnya sampah dari kebun serta taman yang ada di kawasan kampus dan juga sampah organik dari kantin UMN. Setelah bisa membuat sendiri baru kemudian disosialisasikan kepada pihak luar yang kebetulan berkunjung ke UMN seperti dari ibu-ibu PKK RW 035 Kelurahan Bojong Nangka dan sejumlah staf jajaran Korem 052 Wijaya Krama yang keduanya merupakan mitra pengabdian kepada masyarakat UMN.

Pertama mereka diajarkan cara membuat komposter untuk pengolahan sampah menjadi pupuk car organic, kemudian melaksanakannya.

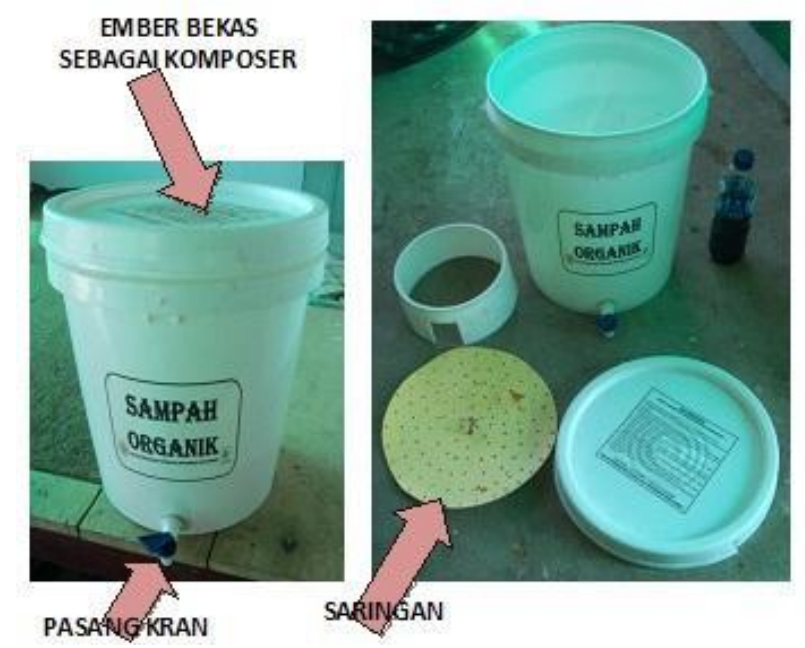

HASIL DAN PEMBAHASAN

Pada tahap awal, Penyusunan program sosialiasi ini dilakukan dengan pembuatan komposter dan uji coba penggunaan pupuk cair kepada masyarakat sekitar.

Persiapan sarana dan prasarana pelatihan. Persiapan ini meliputi penyediaan sarana dan prasarana tempat sosialisasi dan pelatihan.Koordinasi lapangan dilakukan dengan melibatkan Direktur Bumdes Desa Lengkong Kulon daerah binaan UMN.
Tahap pelaksanaan dalam kegiatan pengadian kepada masyarakat ini diantaranya adalah:Pembahasan materi mengenai teknik pembuatan pupuk cair, kemudian mempraktekannya dalam kegiatan masyarakat.mengimplementasikan teori yang telah diterangkan. Semuanya dilakukan

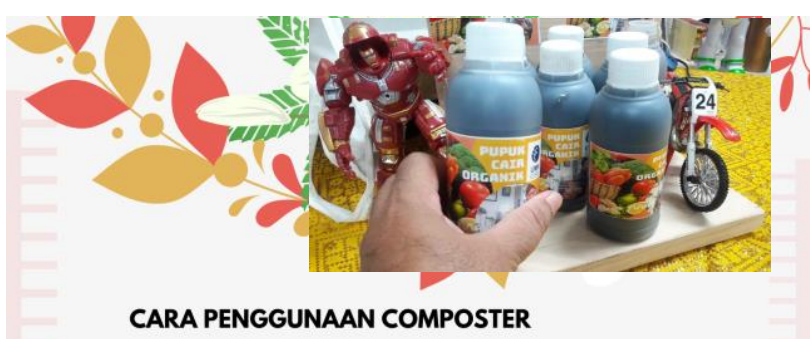

1. Bukalah tutup composter, masukkan sampah pilahan (organik) ke dalam composter.(keadaan sampah boleh utuh atau terpotong-potong)

2.Semprotkan Decomposer bioaktivator (produksi ecomposer untuk kalangan sendiri)

3. Tambahkan sampah organik setiap saat ke dalam composter

4. Kondisikan tutup composter selalu dalam keadaan tertutup rapat.

5. Perhatikan selang aliranpupuk cair,bil telah tampak cairan dalam selang, dar dituangkan untuk dapat digunakan sebagai pupuk tanaman anda.

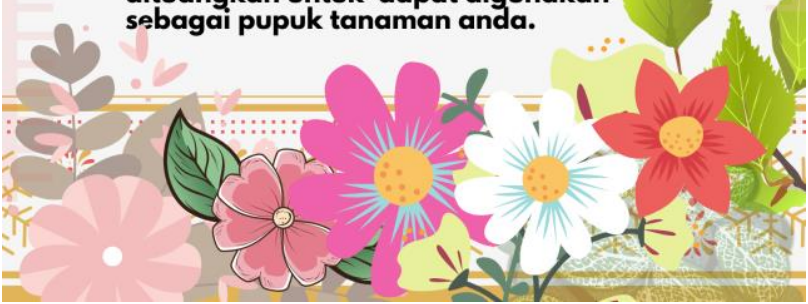

saat sebelum pandemic terjadi yaitu di awal tahun 2020 hingga bulan Agustus 2020. Sosialisasi belakangan agak terkendala karena covid sehingga sebagian pelatihan dilakukan secara daring memenfaatkan zoom dan youtube. Video tutorial pembuatan pupuk cair organik bisa diunduh di link berikut https://www.youtube.com/watch?v=wrjF3EeqA $4 \& \mathrm{t}=12 \mathrm{~s}$

Hasilnya setelah melakukan pembuatan komposter dan ujicoba maka dihasilkan pupuk cair organik yang kemudian didistribusikan kepada masyarakat desa binaan UMN . Di sisi yang lain, para dosen UMN juga menawarkan cara pemasaran digital agar masyarakat sekitar kampus bisa mendapatkan keuntungan material, selain membuat 
kampong menjadi lebih bersih juga bisa menghasilkan keuntungan finansial.

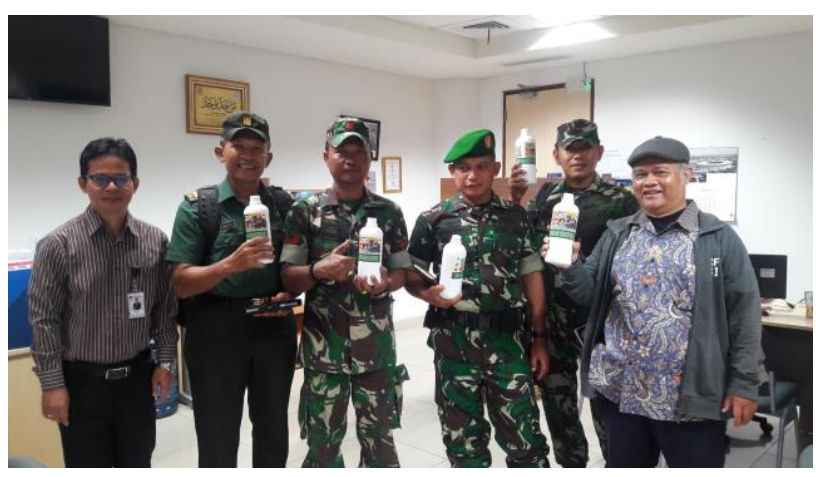

\section{KESIMPULAN}

Kegiatan pengabdian kepada masyarakat Pembuatan pupuk cair organik ini ternyata sangat disukai oleh warga desa binaan. Dan dampaknya adalah mereka akhirnya terbiasa memanfaatkan sampah organik, sampah keluarga untuk dijadikan pupuk cair organik.

Secara umum berikut keunggulan dan manfaat pupuk organik cair jika dibandingkan dengan pupuk anorganik. Kandungan unsur hara makro dan mikro lengkap tetapi jumlahnya sedikit. Dapat memperbaiki keadaan struktur tanah, sehingga kondisi tanah menjadi gembur. Mempunyai daya simpan air / water holding capasity yang tinggi.

Pupuk anorganik akan terakumulasi di dalam tanah dan menyebabkan kekahatan (kekurangan) hara. Tanah yang sering diberi pupuk anorganik lama-kelamaan dapat menjadi keras sehingga menjadi sulit untuk diolah dan mengganggu pertumbuhan tanaman.

Karena itu, pemanfaatan pupuk organik untuk tanah sangat membantu memperbaiki struktur tanah, meningkatkan permeabilitas tanah, dan mengurangi ketergantungan lahan pada pupuk anorganik. Selain itu, pupuk organik juga berperan sebagai sumber makanan bagi mikroorganisme tanah. Efek positifnya, dapat meningkatkan jumlah dan aktivitas mikroorganisme tanah sehingga tanah menjadi gembur dan mudah menyerap air.

\section{REFERENSI}

https://progres.id/agrikultur/miliki-banyak-manfaatbagi-tanaman-ini-cara-membuat-poc.html

https://b-pikiran.cekkembali.com/pupuk-organikcair/

https://tangerangnews.com/kotatangerang/read/31507/Lebaran-Sampah-di-KotaTangerang-Capai-1543-Ton

https://www.youtube.com/watch?v=wrjF3EeqA $4 \& \mathrm{t}=12 \mathrm{~s}$ 